\title{
Control of Localized Nanorod Formation and Patterns of Semi- Conducting CuTCNQ Phase I Crystals by Scanning Electrochemical Microscopy
}

\author{
Aaron K. Neufeld ${ }^{1^{*}}$, Anthony P. O'Mullane ${ }^{2}$, and Alan M. Bond ${ }^{*}$ \\ 1 CSIRO Manufacturing and Infrastructure Technology, PO Box 56, Graham Rd, Highett, 3190 , \\ Victoria, Australia \\ 2 School of Chemistry, Monash University, Clayton, Victoria, 3800, Australia \\ 1 Aaron.Neufeld@csiro.au \\ 2 Alan.Bond@sci.monash.edu.au \\ * Authors to whom correspondence should be addressed.
}

Supporting Information 

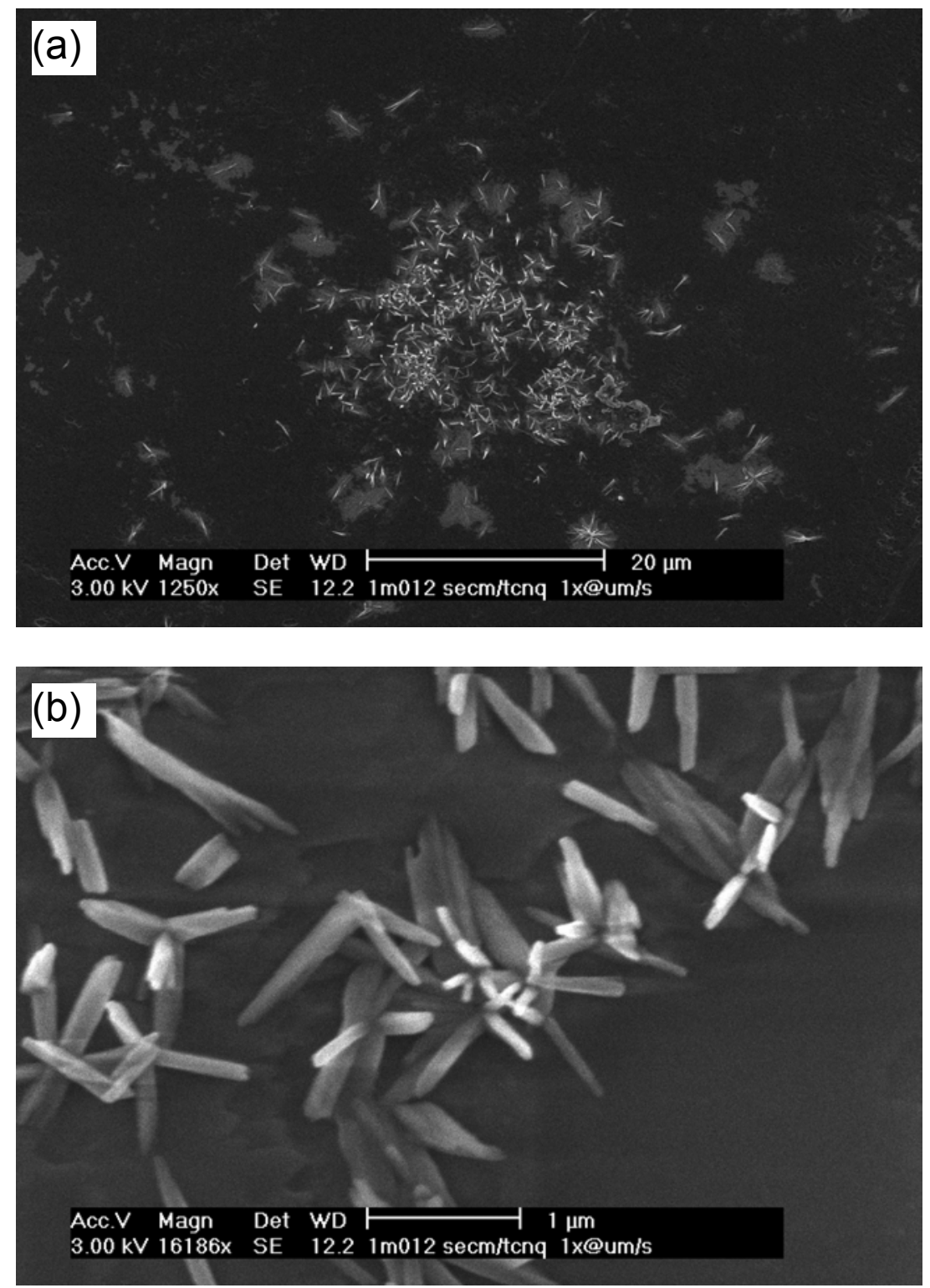

Figure S1: SEM images at low (a) and high (b) resolution after a TCNQ crystal has been approached once under SECM conditions $\left(0.01 \mathrm{M} \mathrm{CuSO}_{4}, 1 \mathrm{mM} \mathrm{VCl}_{3}\right.$ aqueous electrolyte) by a $25 \mu \mathrm{m}$ Pt UME electrode at a rate of $1 \mu \mathrm{m} \mathrm{s}^{-1}$. 

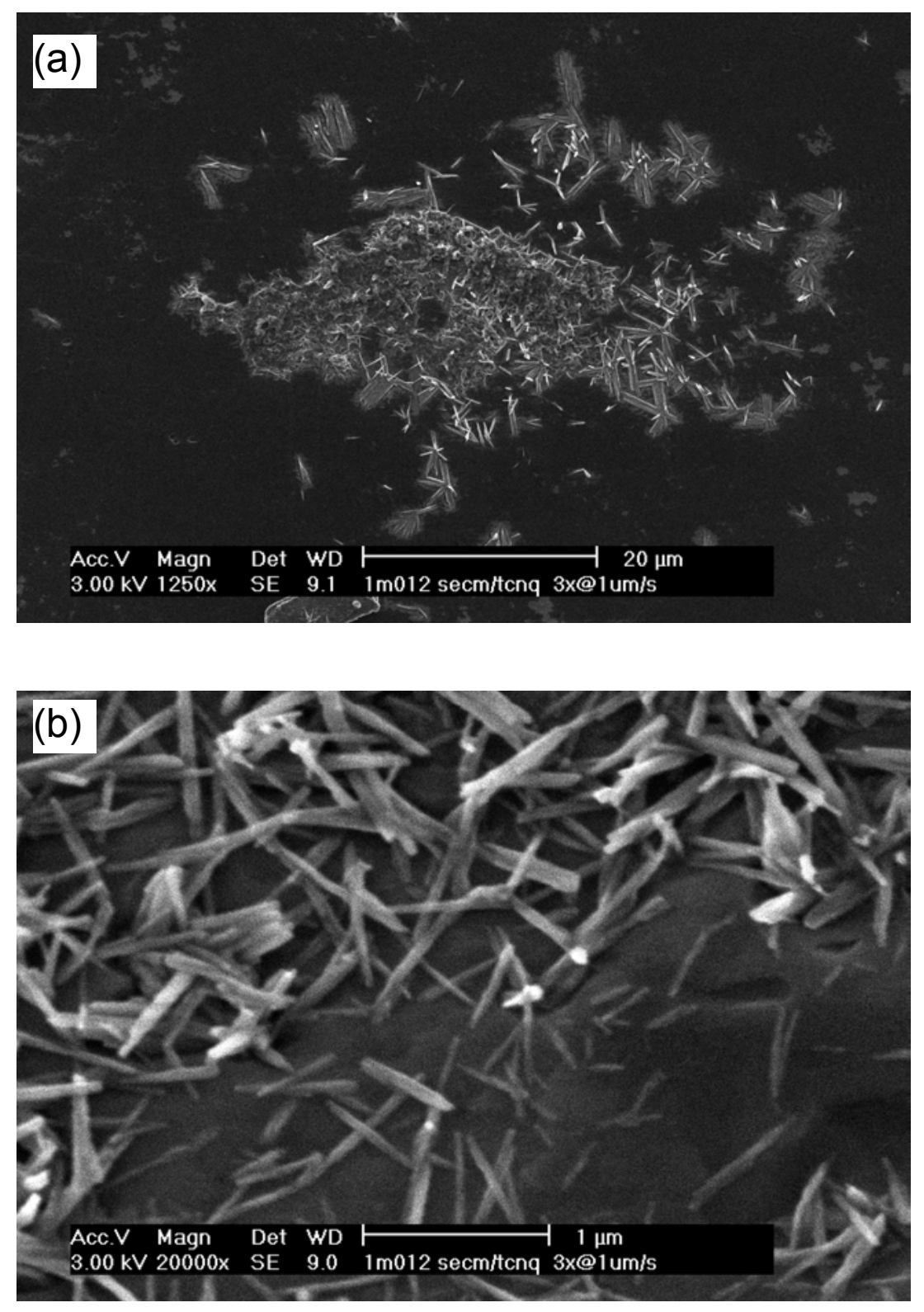

Figure S2: SEM images after (a) and (b) a TCNQ crystal has been approached 3 times under SECM conditions $\left(0.01 \mathrm{M} \mathrm{CuSO}_{4}, 1 \mathrm{mM} \mathrm{VCl} 3\right.$ aqueous electrolyte) by a $25 \mu \mathrm{m} \mathrm{Pt} \mathrm{UME}$ electrode at a rate of $1 \mu \mathrm{m} \mathrm{s}^{-1}$. 

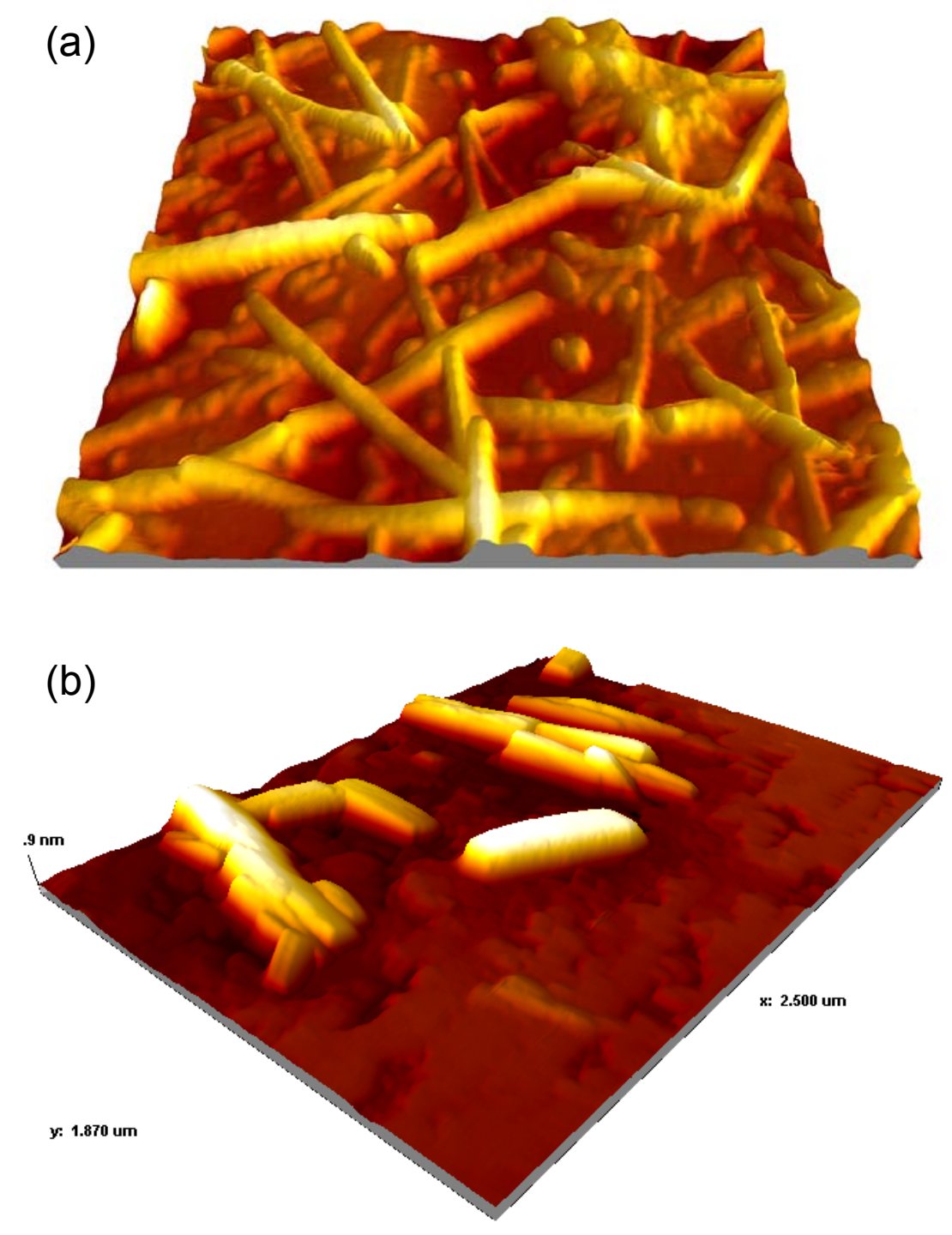

Figure S3: Tapping Mode AFM height images obtained from region 2 as indicated in Fig. 6(a) after a TCNQ surface was approached 7 times under SECM conditions $\left(0.01 \mathrm{M} \mathrm{CuSO}_{4}, 1 \mathrm{mM}\right.$ $\mathrm{VCl}_{3}$ aqueous electrolyte) by a $25 \mu \mathrm{m} \mathrm{Pt} \mathrm{UME}$ electrode at a rate of $1 \mu \mathrm{m} \mathrm{s}^{-1}$. Scan dimensions are (a) $0.8 \mu \mathrm{m} \times 1.2 \mu \mathrm{m}$, (b) $1.9 \times 2.5 \mu \mathrm{m}$. Images are scaled equally in all dimensions. 

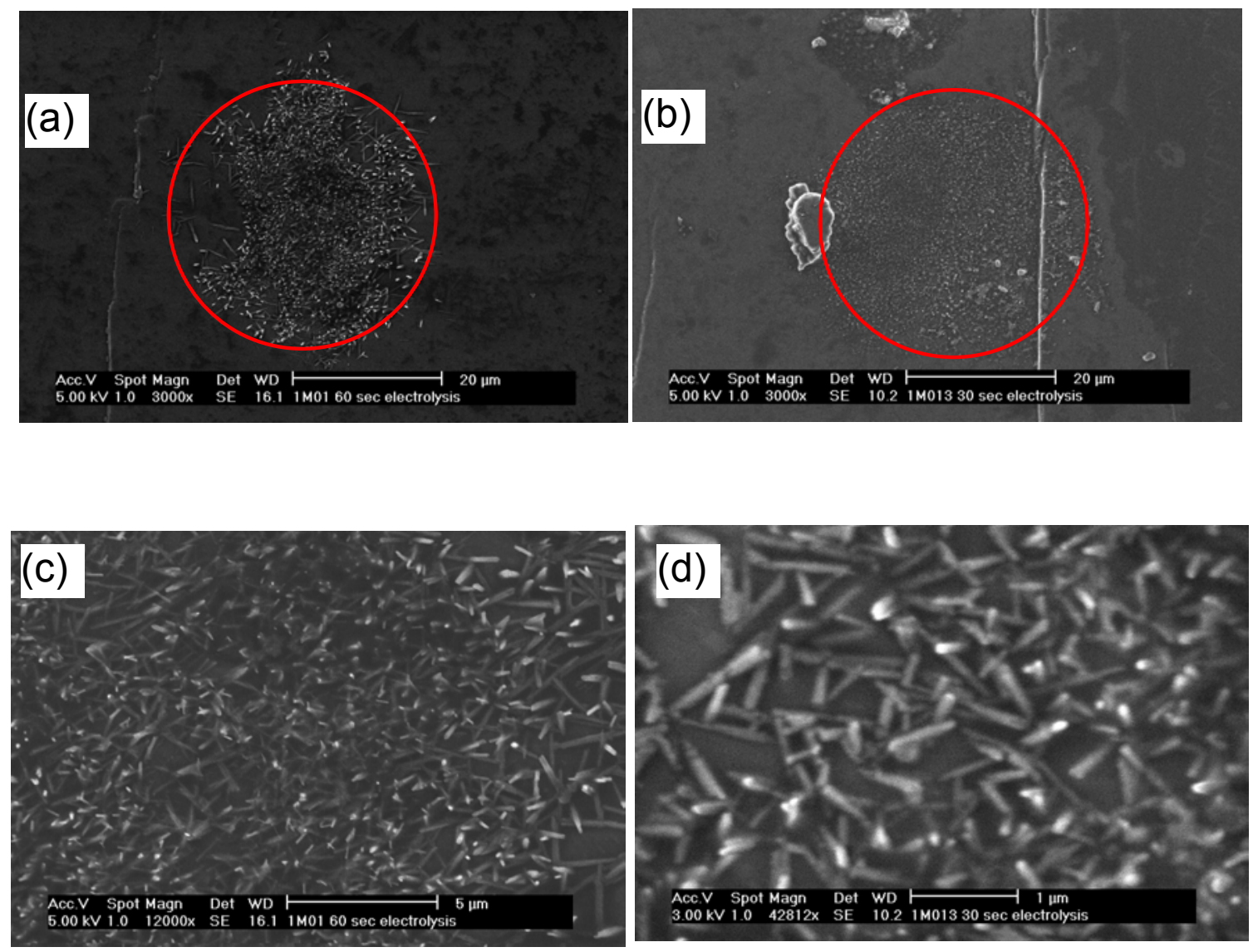

Figure S4: SEM images obtained after a TCNQ crystal has been modified by a $25 \mu \mathrm{m}$ Pt UME electrode held at $-0.065 \mathrm{~V}$ vs Ag wire under SECM conditions $\left(1 \mathrm{mM} \mathrm{VCl}_{3}+0.010 \mathrm{mM} \mathrm{CuSO}_{4}\right.$ electrolyte) at a tip-sample distance of (a and c) $5 \mu \mathrm{m}$ for $60 \mathrm{~s}$ and (b and d) $1.7 \mu \mathrm{m}$ for $30 \mathrm{~s}$. Red circles drawn on (a) and (b) with diameter to $35 \mu \mathrm{m}$ and have been included to aid identification of the modified regions. 

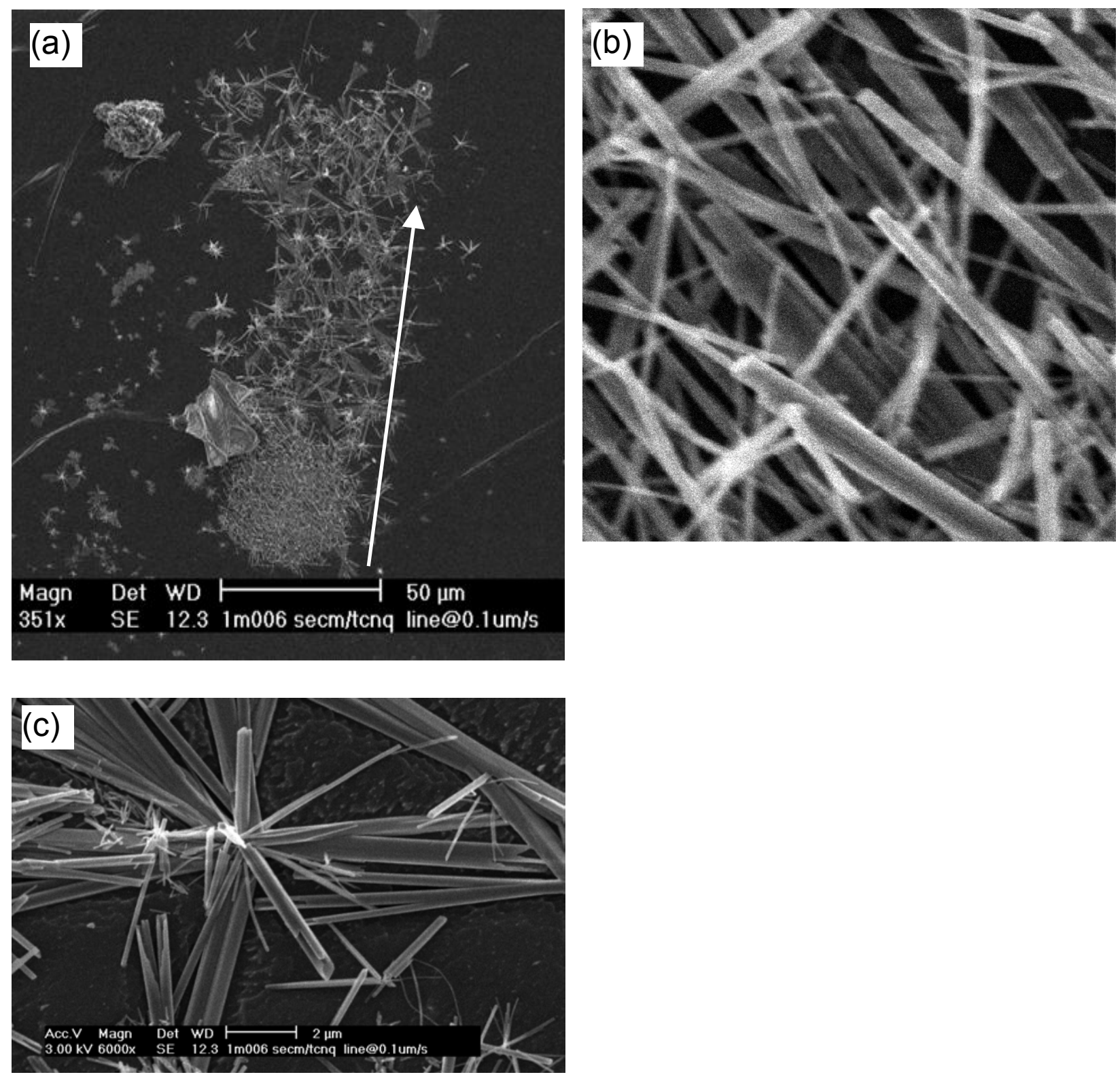

Figure S5: SEM images obtained after by a $25 \mu \mathrm{m}$ Pt UME electrode held at $-0.065 \mathrm{~V}$ vs Ag wire has traversed across the surface of a TCNQ crystal (a) for a distance of $100 \mu \mathrm{m}$ (arrow indicating the scan direction) under SECM conditions $\left(0.01 \mathrm{M} \mathrm{CuSO}_{4}, 1 \mathrm{mM} \mathrm{VCl}_{3}\right.$ aqueous electrolyte) at a rate of $0.1 \mathrm{um} \mathrm{s}^{-1}$ with a tip-sample distance of $5.4 \mu \mathrm{m}$. High magnification micrographs (b and c) show the morphology of CuTCNQ nanowires (b) from the starting point (image size $4 \times 4 \mu \mathrm{m}$ ) and (c) within the line pattern. 

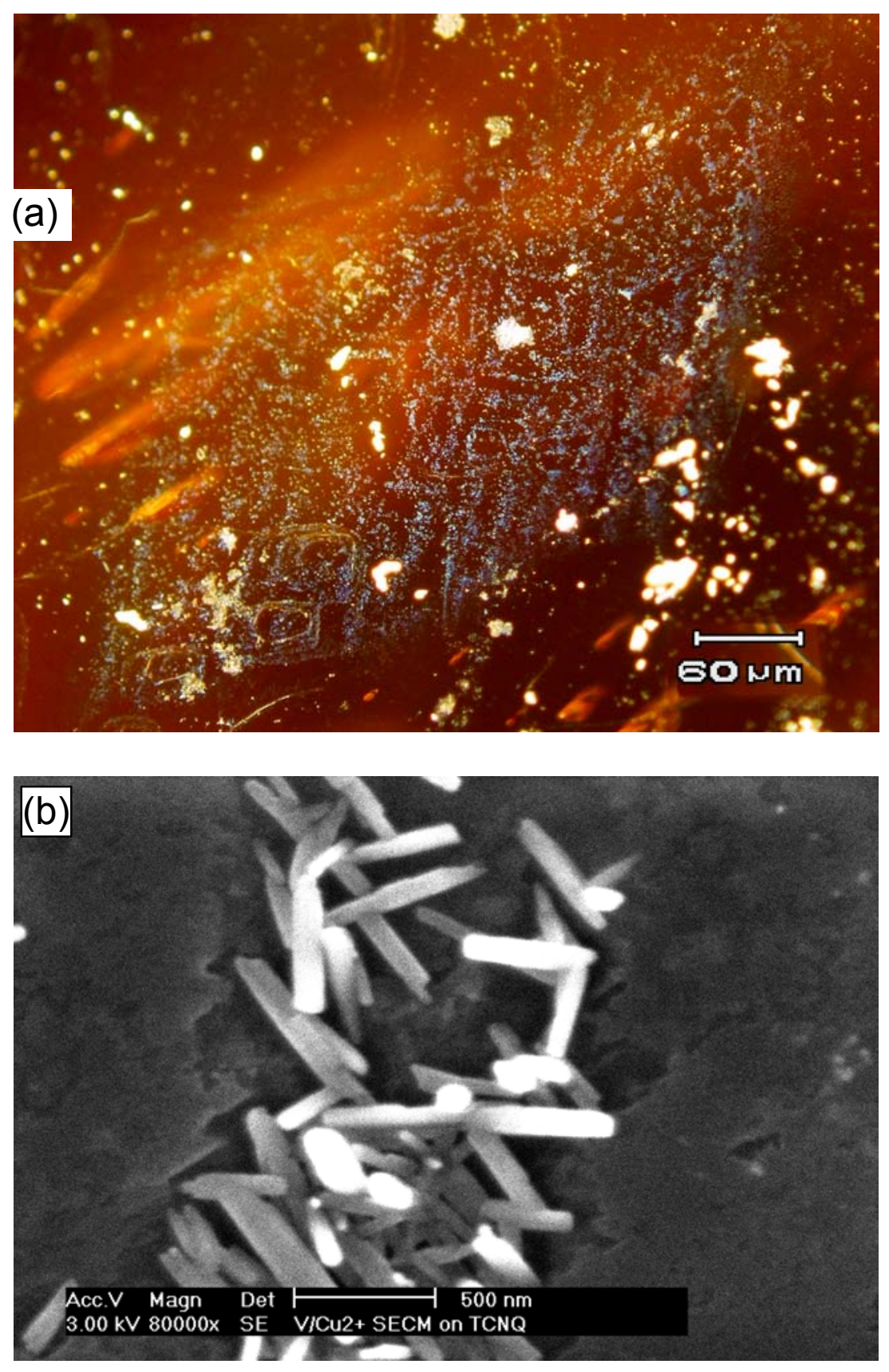

Figure S6: Images obtained after a TCNQ crystal has been patterned by rastering of a $25 \mu \mathrm{m} \mathrm{Pt}$ UME held at $-0.065 \mathrm{~V}$ vs $\mathrm{Ag}$ wire under SECM conditions $\left(1 \mathrm{mM} \mathrm{VCl} \mathrm{VC}_{3}+10 \mathrm{mM} \mathrm{CuSO}_{4}\right.$ electrolyte) over a $300 \times 300 \mu \mathrm{m}$ area and a UME tip-sample distance of $10.5 \mu \mathrm{m}$. (a) visiblelight microscope image displaying blue coloured CuTCNQ crystals and (b) SEM image at high magnification highlighting the fragmentation that occurs on CuTCNQ formation. 